\title{
Por uma pedagogia da pesquisa educacional e da formação de professores na universidade
}

\section{For a pedagogy of educational research and teacher education in university}

\section{Denice Catani ${ }^{1}$}

\begin{abstract}
RESUMO
O texto analisa e discute aspectos e possibilidades para a formação de professores nas universidades. Apresenta hipóteses para a constituição de uma pedagogia da pesquisa e uma pedagogia da formação de professores. Para tanto, retoma a noção de habitus de P. Bourdieu, e introduz duas perspectivas para o trabalho formador: a cultura da atenção como perspectiva a ser atingida na educação docente e os estilos didáticos como disposições e marcas da ação pedagógica construídas pelos professores no exercício da profissão. Articulando esses três conceitos à valorização e constituição de histórias de formação e histórias de relações com o conhecimento e o trabalho, constituem sugestões a serem consideradas pelos cursos de Licenciatura e Pedagogia.

Palavras-chave: Formação de Professores; Pedagogia da Pesquisa; Habitus; Cultura da Atenção; Estilos Didáticos.
\end{abstract}

\begin{abstract}
The paper analyses and discusses aspects and possibilities to teacher education in universities. It shows ideas about the constitution of a pedagogy of research and a pedagogy of teacher education. Therefore, it uses the notion of habitus by P. Bourdieu and it introduces two perspectives on how to educate: the culture of caring as a perspective to be done in teacher's education and the didactic style as dispositions and brands of pedagogic action built by teachers. By connecting these three aspects to the apprecia-
\end{abstract}

1 Professora Titular da Faculdade de Educação da Universidade de São Paulo - Brasil. 
tion and the constitution of teacher education stories and stories of relations with the knowledge and work new guidelines start to be considered by Licenciature and Pedagogy courses.

Keywords: Teacher Education; Pedagogy of Research; Habitus; Culture of Caring; Didactic Style.

\section{Introdução}

Muito tem sido dito sobre a universidade e a formação de professores, sobre as relações entre ensino e pesquisa nesses processos e sobre a necessidade de reformulações constantes dos cursos. O que aqui se tentará acrescentar a esse muito é produto de reflexões desenvolvidas ao longo de uma experiência, também extensa, de trabalho na universidade. É tanto fruto de trabalhos de pesquisa no espaço da formação de professores quanto no da história da educação brasileira. Trata-se, aqui, de um conjunto de reflexões que se beneficiam de modo ensaístico de autores e ideias, não necessariamente consagrados na área, mas que se mostram férteis ao orientar buscas sobre as práticas do ensino universitário. A proposição que me foi feita era a de produzir um texto acerca da "pesquisa como formação de um habitus profissional: o que os processos formativos da universidade têm a dizer". Guiei-me pela proposta, concretizando à luz da minha história de relações com a questão. Preocupa-me discutir os modos próprios de ensinar aos que se ocuparão do ensino ou os modos de formar quem cuidará da formação de outros. Será este o cerne do que aqui se desenvolverá, e, por tal razão, será importante compreender os lugares do ensino e da pesquisa nesse processo e compreender as cisões cultivadas entre formação para a pesquisa e formação para o ensino - tal como se configuram em nosso ensino superior.

\section{Para questionar a natureza dos estudos, conhecimentos e discur- sos educacionais no Ensino Superior}

O modelo predominante de desenvolvimento dos conhecimentos científicos ou acadêmicos, na área educacional, tem sugerido uma rápida assimilação de informações, de lógicas de argumentação, de conceitos e de vocábulos que, no meu entender, não favorece a apropriação detida das várias contribuições de autores e teorias que podem nos auxiliar na compreensão dos nossos problemas 
relativos à escola e aos processos formadores. A velocidade da incorporação, produção e ultrapassagem de explicações e vocábulos na área pedagógica sugere a necessidade de voltar a se questionar a natureza dos estudos / conhecimentos e discursos educacionais. Relativamente a alguns autores, valeria a pena proceder a novas leituras e demorar-se "em sua companhia" de modo a pensar com eles (ou a partir deles) os problemas que são nossos. A potência do pensamento, de alguns estudiosos de ciências humanas, oferece-se, para a área educacional, de modo tal que ainda cabe explorar. Do mesmo modo, também a maneira pela qual cada pesquisador e docente do ensino superior da mesma área produziu estudos e reflexões pode gerar retomadas explicitas e, ainda, fecundar o pensamento acerca de novas realidades e questões. A consideração dessas ideias apresenta-se aqui por dupla razão: para enunciar a retomada que quero propor para a obra de alguns estudiosos e para sustentar que pretendo produzir novas articulações acerca do problema das práticas de ensino na formação universitária, retomando também algumas proposições enunciadas noutros trabalhos que realizei.

Permito-me, assim, retomar C. Lévi-Strauss, pelas mãos de P. Bourdieu que, de forma perspicaz, o transcreve no início do seu texto, pouco mencionado entre nós - "Sistemas de Ensino e Sistemas de Pensamento" - publicado originalmente em 1967. Trata-se de um trecho de Tristes Trópicos no qual L. Strauss fala sobre "as técnicas e os ritos do ensino francês de filosofia". Diz ele:

Lá, comecei a apreender que qualquer problema, grave ou fútil, pode ser liquidado pela aplicação de um método sempre idêntico, que consiste em opor dois pontos de vista tradicionais da questão; em introduzir o primeiro pelas justificações do senso-comum, em seguida destruí-lo por meio do segundo; enfim em rejeitá-los ambos, graças a um terceiro que revela o caráter igualmente parcial dos dois outros, reduzidos por artifícios de vocabulário aos aspectos complementares de uma mesma realidade: forma e fundo, continente e conteúdo, ser e parecer, contínuo e descontínuo, essência e existência etc. Tais exercícios logo se tornam verbais, fundados numa arte do trocadilho que toma o lugar da reflexão, as assonâncias entre os termos, as homofonias e as ambiguidades fornecendo progressivamente a matéria dessas surpresas de teatro especulativas, em cuja engenhosidade se reconhecem os bons trabalhos filosóficos [...].

Para ele, tratava-se de algo como o aprendizado de "uma ginástica" com a qual se poderia adquirir um modo de tratar qualquer problema. Acrescentava: "[...] Não apenas o método fornece uma chave-mestra, mas incita a somente perceber, na riqueza dos temas de reflexão, uma forma única, sempre a mesma, 
salvo algumas correções elementares" (apud BOURDIEU, 2005). Bourdieu utiliza-se desse texto para trazer à tona a questão da transmissão cultural e nela o papel da escola. Para falar dos modos de pensamento que se adquirem, implícita e explicitamente, que são utilizados, consciente ou inconscientemente, para guiar ações e percepções e para gerar novas respostas à realidade. O que Strauss toma como exemplo, na sua própria formação: o aprendizado de esquemas de solução de problemas na dissertação filosófica sugere que se indague sobre a natureza dos aprendizados que, nos cursos de ciências humanas, se tem favorecido para os alunos nas universidades. O caso citado por Strauss é de um outro tempo e de um outro lugar, porém pode-se indagar sobre o que aprendem mesmo os que vão ser professores. Para além das disciplinas nomeadas no currículo, diante dessa questão, intrigou-me, desde os anos 1980, algumas ideias correntes a esse respeito (CATANI, 1987). Naquele momento, examinei aquilo que professores atuantes e alunos de Pedagogia e Licenciatura diziam sobre sua própria formação. Acreditei ter detectado aspectos importantes das crenças que sustentavam as propostas de formação, algumas das quais permanecem intocadas: de um lado a pressuposição quanto à eficiência de um “saber" pedagógico a ser simplesmente incorporado à formação teórica dos professores, e de outro a crença na figura de um "bom professor" como ideal de excelência, para o qual a posse de certos atributos (em termos de informação e regras de conduta) deve ser garantia de êxito na atuação, ideia esta que direciona também a própria produção de pesquisas sobre o ensino. Caberia retomar um tal aspecto que, em grande medida e mesmo sem que isso se explicite, essas pressuposições parecem orientar as práticas e a organização do ensino, ainda hoje. Ao discutir o problema dos conhecimentos pedagógicos ensinados aos professores, assinalei algo que teria oportunidade de explorar posteriormente. Considerei as dificuldades decorrentes dessa crença num conhecimento orientador da ação e que minimizava a dimensão pessoal e as relações dos professores ou futuros professores com os conhecimentos, áreas ou disciplinas. A crítica referia-se ao fato de que não se cultivava na formação dos futuros professores aquilo que seria de se esperar, ele o fizesse com relação aos seus alunos, ou seja, o desenvolvimento de um conjunto de disposições férteis com relação ao mundo e ao conhecimento. 


\section{A formação docente e a revisão dos modos de produção do conhe- cimento para integrar consciência e reflexão a ações transforma- doras}

Mediante o recurso a R. S. Peters que desenvolvera um texto acerca da "educação como iniciação" (1979) sublinhei sua ideia de que isto, envolve mais do que familiarizar-se com o conhecimento, envolve aprender os modos de produção desse conhecimento e sua presença no mundo. Algumas perguntas daí decorreram: o que se tem feito, efetivamente, para que os professores compreendam, enquanto se educam, a natureza do que é veiculado sobre ensino? E, além disso, como os cursos de formação de professores têm contribuído para que os indivíduos sejam capazes de analisar produtivamente suas experiências, de explicitar as razões de suas próprias escolhas, ou ainda de lançar um olhar arguto ao domínio das soluções pedagógicas suspeitando de caminhos já abertos? E também: de que forma os cursos tem levado os professores a integrarem a consciência e a reflexão sobre a experiência da possibilidade de ações transformadoras de suas práticas? Certamente o tempo decorrido desde essas constatações permitiu que muito fosse feito e, em alguma medida, as praticas de formação que exploram trajetórias pessoais e histórias de escolarização, de relações com a escola e com o trabalho contribuem, de forma inegável para a superação de parte dos limites impostos pelo que estava contido nas indagações feitas naquele momento. Embora reconhecendo que, muitos dentre nós, professores universitários, dispunham-se a reformular os cursos de formação docente, ainda restava a questão de rever essa formação repensando igualmente o trabalho pedagógico dos professores desse nível de ensino.

Há muito chama a atenção a carência de estudos sobre a "didática dos que ensinam didática" e da didática empregada na preparação para a docência. $\mathrm{Na}$ verdade, essa questão remete para a de se saber que espécie de atitude ou disposição temos cuidado de prover com relação ao que se considera como "conhecimentos educacionais". Há muito não se menciona o caráter exemplar que a ação dos mestres tem sobre os alunos. Tal fato parece ser considerado "fora de moda" e foi expurgado dos discursos sobre ensino. Entretanto, valeria a pena sustentar que, de formas muito variadas e até mesmo insuspeitas essa peculiaridade do exemplo dos professores se exerce. Tem se evidenciado o fato de que um dos elementos importantes da construção de estilos didáticos pessoais, aos quais voltaremos a seguir, é a figura de um ou mais professores com quem aprenderam em seu percurso escolar. Talvez não haja muito o que ser tematizado a respeito, porém não me parece ser esse um elemento sem valor. 
Poder-se-ia, ainda, retomar um outro texto de P. Bourdieu, nas considerações que faz juntamente com Chamboredon e Passeron em $A$ Profissão do Sociólogo (1999) para se encontrar férteis recomendações para a educação de cientistas. Explicitando o que consideram uma "pedagogia da pesquisa" referem-se à possibilidade de aprender a inventar o conhecimento a partir de um testemunho sistemático e do acompanhamento das atividades de quem produz a investigação e o conhecimento. Pensa ele que não se adquire um ofício como o da pesquisa mediante a obediência a regras previamente dadas, mas sim pelo contato com os que podem mostrar esse fazer. Num certo sentido, aqueles que serão professores testemunham ao longo de toda a sua formação modalidades diversas do exercício do trabalho docente. As oportunidades para compreender como se dá a construção desse trabalho e dos conhecimentos sobre ele são mais raras. Temos visto, por exemplo, que a integração precoce dos alunos universitários em grupos de pesquisa tem ocasionado muito bons resultados. Observam-se os processos de "iniciação científica" como situações privilegiadas de contato com a produção dos pesquisadores, porém, destinados a um número pouco expressivo de participantes. Entendo que algo desse investimento formador deveria generalizar-se a todos os alunos - aos que serão professores, em especial.

Sustentei, em texto escrito há tempos "A didática como iniciação: uma alternativa no processo de formação de professores" (CATANI, 2001, p. 125) que seria legítimo pensar como Peters faz para a educação em geral que, no seu entender " $[\ldots]$ consiste em iniciar os outros em atividades, modos de condutas e pensamento, que possuem regras intrínsecas, referentes ao que é possível para a ação, para o pensamento e para o sentimento, nos vários graus de competência, relevância e gosto". Assim, poder-se-ia entrever modalidades de educação pedagógica que iniciassem na compreensão dos processos de formação. Seria necessário que, por exemplo, a didática se propusesse a estudar as "questões de ensino" mediante a análise de sua emergência nas situações institucionais, concretas, no entrecruzamento de um conjunto complexo de variáveis e mediante a interpretação e estabelecimento da crítica de discursos que exprimem a compreensão dessas questões.

Essa ideia de "iniciar" pela familiaridade com as regras que organizam atividades, conhecimentos e comportamentos ajuda a entender que a educação de professores deve se dar tanto no sentido que acabamos de referir quanto na compreensão do enraizamento pessoal dos nossos comportamentos e preferências quanto aos modos de ensinar e estar nas situações pedagógicas. Iniciar no que tange aos professores implica, então, em familiarizar-se com as regras e com as significações pessoais dos processos formadores. Isso não quer dizer habilitar o sujeito a obedecer a regras ou reproduzir procedimentos e sim saber da lógica interna dos conhecimentos e atividades. 


\section{As práticas em ação na preparação e exercício da profissão docen- te e como mobilização criadora}

A esse propósito é útil recorrer à retomada que Perrenoud faz de considerações de Bourdieu a propósito da maneira pela qual a consecução de práticas não se limita à obediência a regras:

Qualquer tentativa de fundar uma prática em obediência a uma regra explicitamente formulada seja no âmbito da arte, de moral, da política, da medicina ou até da ciência (que se pensa obedecer às regras do método), confronta-se com a questão das regras que definem a maneira e o momento oportuno - Kairos, como diziam os sofistas - da aplicação das regras ou, como se dizia e bem, de por em prática um repertório de receitas e de técnicas, em suma da arte da execução através da qual se reintroduz, inevitavelmente, o habitus". A essa noção nos referiremos mais adiante (BOURDIEU, 1972, p. 199-200 apud PERRENOUD, 1993, p. 40).

A questão que se impõe para os próprios professores universitários é, então, qual a natureza das relações que cada um de nós mantém com o conhecimento e, mais ainda, quais as relações e disposições que estamos com nossas práticas de formação favorecendo aos futuros professores? A partir dessa questão enuncia-se uma dupla referência: de um lado, as práticas de formação, de outro, as relações com o conhecimento que essas práticas favorecem. Entendo que a unificação dessa dupla referencia é possível nas situações em que os indivíduos discutem suas práticas, sua história de formação e suas relações com os conhecimentos, nas situações nas quais se defrontam com múltiplas histórias e modalidades pessoais de relações com a realidade. No momento em que acompanham tematizam a construção do trabalho docente e dos estilos didáticos dos professores em ação. Nessa perspectiva, não é demais pensar que os processos de iniciação possam aí se configurar pela convergência do trabalho de aquisição de informações, observações, sistematizações e reflexões que integram o individual e o social. Trata-se menos de saber quais as disciplinas que proverão tal aprendizado do que de conceber essa possibilidade como uma disposição presente em todas as disciplinas e para todos os alunos. Nessa medida, talvez se possa dizer que se deve generalizar a "iniciação científica" para todos - no sentido aqui aludido e, tanto quanto possível no sentido corrente da prática e ainda quando o objeto de investigação fosse o ensino. Acrescentar-se-ia, nesse último caso, uma relação 
pedagógica mais fecunda e uma oportunidade ímpar para o desenvolvimento de atitudes e relações significativas no processo de descobrir e inventar. Poderíamos nos perguntar, assim, sobre essa alternativa de formar professores e pesquisadores educacionais capazes de criar (inventar) em seu próprio trabalho. No dizer de Bourdieu, aliás:

Da mesma forma que o conhecimento da anatomia não é a condição suficiente de um procedimento correto, assim também a metodologia, dizia Weber, 'não é a condição de um trabalho fecundo'. No entanto, se é inútil esperar descobrir uma ciência da maneira de fazer a ciência e esperar da lógica algo diferente de uma forma de controlar a ciência em vias de se fazer ou validar a ciência já constituída, ocorre que, como observa Stuart Mill, 'a invenção pode ser cultivada', o mesmo é dizer que uma explicitação da lógica da invenção, por mais parcial que seja, pode contribuir para a racionalização da arte de inventar (BOURDIEU, 1999, p. 15-16).

A propósito das disciplinas integrarem os cursos, embora elas proliferem com excessiva rapidez e tenhamos, nos últimos anos, incorporado várias delas, fundamentalmente deveriam ser preservadas com ampla presença das delimitações tradicionais que podem ter um papel estruturante no desenvolvimento do pensamento e ação pedagógica dos que vão ser professores. Refiro-me por exemplo a uma efetiva presença da filosofia, sociologia, história e outras, além da instauração de significativos espaços para o estudo de questões de ensino, tais como, avaliação, disciplina, relações pedagógicas, simultaneamente aos estudos acerca do ensino especifico de cada área². Nesse último caso não penso apenas no estudo dos métodos de ensino destinados à matemática, geografia, línguas ou algo assim, mas também em formas de mobilizar todos os outros conhecimentos envolvidos: o conteúdo especifico disciplinar, a psicologia da aprendizagem e do desenvolvimento e uma acurada compreensão de como se produzem e circulam os conhecimentos específicos da área da qual a disciplina pertence.

2 Um modo diferenciado de tratar o problema da avaliação, inscrevendo-o no universo das possibilidades aqui apresentadas e incluindo a consideração das ressonâncias pessoais dos processos vividos no percurso escolar pode ser lido em CATANI, D. B.; GALLEGO, R. C. Avaliação. São Paulo: Ed. Unesp, 2009. 


\section{Estilos didáticos e habitus na construção do trabalho docente: a perspectiva pessoal e social}

A questão é saber até que ponto as práticas que são postas em ação na preparação docente conduzem à mobilização criadora, necessária a um fecundo exercício da profissão. Sabemos bem que em não sendo assim, vingará a situação na qual as esperanças de ação bem sucedida serão depositadas em métodos, técnicas e procedimentos padronizados e "cegos" para a realidade pessoal e social de alunos e professores. Apenas uma adequada reflexão acerca desses limites e da potência de criação dos estilos didáticos de cada docente contribuiria para prevenir tais riscos. Entende-se que os estilos didáticos são modalidades inventadas pessoalmente a partir dessa mobilização criadora dos conhecimentos, experiências, história pessoal e variações de práticas já conhecidas. Os estilos didáticos permitem justamente a construção do trabalho na perspectiva da sua significação pessoal e social, como acentuei anteriormente.

Quando nosso próprio espaço de trabalho é a formação alheia as dimensões da nossa história pessoal de formação ganham maior relevo. É preciso sempre levar em conta que as práticas pedagógicas profissionais dos indivíduos devem muito ao que eles experimentaram ao longo do seu desenvolvimento. A retomada explícita desses processos deve, assim, contar com espaços específicos no interior dos cursos de preparação para a docência. O núcleo de uma iniciativa dessa natureza poderia envolver atividades como as seguintes:

a) a elaboração acompanhada da história de formação e das trajetórias de escolarização;

b) a discussão da natureza das relações mantidas com a escola, os professores, os conhecimentos;

c) a análise e discussão de estilos didáticos de professores universitários do próprio curso;

d) o estudo sistemático das possibilidades e limites da construção dos estilos didáticos no exercício docente.

Em processos de formação contínua para professores do Ensino Fundamental (cursos de especialização) concretizados na Faculdade de Educação da USP tem se trabalhado - a partir de todo um investimento na compreensão das especificidades da memória, formação e narrativa, além de um estudo detido da noção de "habitus" e de suas formas de construção social e profissional - na produção da análise pessoal do estilo didático de cada um dos professores. Muitas vezes a situação de buscar descrever aquilo que é próprio, marcante e individual no exercício do seu próprio trabalho constitui um desafio produtivo. Articular a descrição dos 
traços peculiares às próprias ações pedagógicas, à análise das formas da produção dessas ações e daquilo que as sustentam, como ideias e representações, permite o reconhecimento do estilo pessoal e favorece investimentos de aprimorá-lo. Em processos de formação inicial, iniciativas dessa natureza são levadas a efeito no que tange aos quatro aspectos acima mencionados e no interior do desenvolvimento de disciplina como Didática, por exemplo. O ideal, no entanto, seria constituir espaços específicos para tal fim, de vez que a necessidade de fazer convergir diferentes informações, e mesmo leituras e explicações, demanda tempo nem sempre disponível face às urgências de cumprimento de programas. Não se trata, simplesmente, de pedir que as pessoas escrevam suas histórias ou descrevam suas práticas, trata-se de muito mais. Trata-se de prover elementos teóricos e articulações analíticas que ensejem a construção de percepções e interpretações aptas a promoverem um movimento de compreensão das formas pelas quais o sistema social está representado em nossos atos, comportamentos e obras. Considero que estamos em condições de preservar o lugar das disciplinas tradicionais e ao mesmo tempo construir espaços integradores para outros procedimentos nos cursos de educação de professores.

Uma disposição como a que se acaba de exemplificar constitui, por excelência, um modo de formação / iniciação nas maneiras de compreender as relações com o conhecimento e com as práticas educacionais que se fazem tanto pela explicitação dos determinantes sociais quanto individuais da vida dos agentes. E é mesmo nessa perspectiva que a consideração da noção de "habitus", tal como a circunscreve Bourdieu, vem auxiliar o entendimento do trabalho e da profissão docente, desde a retomada do conceito em suas implicações pedagógicas feitas por Perrenoud, no início dos anos 1990, ao procurar explicitar as ações pedagógicas dos professores.

Retomava as palavras de Bourdieu para referir-se ao:

[...] sistema de disposições as experiências passadas, funciona, em cada momento, como uma matriz de percepções, de apreciações e de ações, e torna possível a concretização de tarefas infinitamente diferenciadas, graças às transferências analógicas de esquemas que permitem resolver os problemas da mesma natureza (BOURDIEU, 1972, p.178-179 apud PERRENOUD, 1993, p. 39).

Tal conceito propicia que se analisem ações do ponto de vista de sua geração ou produção e faz pensar na multiplicidade de ações possíveis as diferenciadoras dos indivíduos a partir de configurações biográficas, situações 
presentes, necessidades e condições ${ }^{3}$. Invoca e integra como se assinalou, dimensões individuais e sociais.

Pelo que se expôs até o momento acerca da formação e iniciação, da possibilidade de formar professores como se formam pesquisadores, da compreensão que se pode derivar da noção de habitus na análise das práticas e do trabalho pedagógico e da hipótese de investimento no entendimento de como se constroem os estilos didáticos pessoais, ainda vale a pena explicitar um norte ao qual deve tender o processo educativo para o magistério.

\section{A constituição dos sujeitos nas dimensões da cultura da atenção}

Trata-se da proposição de uma cultura da atenção na educação de professores, entendida como geradora da capacidade de situar-se nas realidades sociais, referir-se às realidades científicas e intelectuais, ancora-se nas realidades artísticas. Nada há que a psicologia, a sociologia ou a história, por exemplo, nos possa oferecer para a formação se o ancoradouro de suas interpretações não incluir, para os sujeitos que delas se nutrem, a possibilidade de reconhecerem-se como os sujeitos desses modos de saber.

O pensamento de Boaventura Souza Santos guarda, a propósito, em seus escritos mais e menos recentes lições inestimáveis. Quando ele se refereas três formas de racionalidade da modernidade nomeando-as, como outros já o fizeram, como a cognitivo-instrumental das ciências, a racionalidade moral-prática do direito e da ética e a racionalidade estético-expressiva das artes e da literatura nos sugere um traçado para a ambição de formação dos nossos sujeitos. Que no mínimo, compreendendo esses modos de relação com a realidade, soubéssemos os modos pelos quais todos os humanos existem de maneira que pudessem formálos melhores. E não é para a evidência dessa "perfectibilidade" que acenamos todos ao apostar na educação? Por outro lado, é também este autor que num breve texto intitulado Um discurso sobre as ciências (1987), em passagem exemplar que nomeia como "Todo o conhecimento é auto-conhecimento" adverte sobre a onipresença humana, se assim se pode dizer, no empreendimento científico.

3 Uma retomada e análise sistemática das potencialidades da noção de habitus para entendimento da educação e do trabalho de professores foi elaborada por LUGLI, R.S.G. em "A constituição social do indivíduo". In EDUCAÇÃO - Biblioteca do Professor, vol. Bourdieu Pensa a Educação, n.5, 2006, p. 26/35. Vale a pena sublinhar que o numero especial da revista contém outros textos que, em linguagem acessível e com um rigor digno de nota, analisa diversos aspectos da obra do sociólogo. 
Noutra circunstância fui à mesma fonte para apropriar-me de arguta observação acerca do caráter autobiográfico da ciência por ele identificada desde - e mesmo - as palavras do Discurso do método quando Descartes asseverou que "gostaria de mostrar, neste Discurso, que caminhos segui; e de nele representar a minha vida como num quadro, para que cada qual a possa julgar e para que, sabedor de opiniões que sobre ele foram expendidas, um novo meio de me instruir se venha juntar àqueles de que costumo servir-me" (SANTOS, 1987, p. 53). Argumentará, em seguida, o autor para sublinhar o quanto essa dimensão autobiográfica comparece na ciência contemporânea associada a novos modos de sobrevivência ou "[...] a uma outra forma de conhecimento, um conhecimento compreensivo e íntimo que não nos separe e antes nos una pessoalmente ao que estudamos" (1987, p. 53).

Em algum sentido para ele "todo conhecimento científico é autoconhecimento" e por consequência todo desconhecimento é autodesconhecimento. Antes de prosseguir, algumas palavras para enunciar as relações que quero construir. Nossas concepções norteadoras de uma educação para professores não deveriam partir dessa familiaridade para com os sentidos da ciência e do conhecimento de modo a tornar as "questões de saber" questões de todas as pessoas? Dito de outro modo, por que reformularemos o currículo se deixarmos intactas as possibilidades e impossibilidades de alterar as relações das pessoas com esses saberes?

Uma cultura da atenção inclui, necessariamente, essa disposição para reconhecer-se nos empreendimentos da ciência, da arte e da ética como sujeitos. Mas é óbvio que tal disposição é ela própria obra de educação. E é evidente também que, se vamos iniciar alguém (no sentido de PETERS, 1979) e é bem disto que se trata quando se fala do trabalho docente, é de se esperar que se conte, de saída e da parte dos professores, com relações fecundas e pessoais com os modos de saber do mundo.

Para dar apenas um exemplo das formas pelas quais historicamente o Estado e suas instâncias diversas construíram maneiras de identificar os professores pode-se dizer que, para o caso brasileiro, já se conhecem, do ponto de vista histórico, os movimentos pelos quais, ao longo das décadas de cinquenta e sessenta, começaram a se impor novas concepções da excelência da formação docente a partir de saberes científicos e técnicos que deveriam ser produzidos em parte pelos centros regionais de pesquisa, associados ao INEP (Instituto Nacional de Estudos e Pesquisas Educacionais) e postos a circular para inspirar transformações políticas e praticas (LUGLI, 2002).

Essas novas concepções devem ter colaborado, de algumas maneiras que precisam ainda ser melhor analisadas, para a difusão de um sentimento já referido por professores do período de pouca valorização de sua experiência de trabalho no ensino. A categoria "experiência" passou, aos poucos, a ser muito insuficiente diante da necessidade de novos métodos, novas formações, novos 
cursos. A referência aqui a tais fatos quer servir a um intento de chamar a atenção para o modo como temos cuidado também pouco dos processos de enraizamento da formação e como estamos pouco atentos aos sentimentos e relações que os sujeitos constroem para sua inserção na realidade. Certo está e passa da hora de lembrar as maneiras como os sentidos e relações com a cultura, a escola e outras instâncias da vida social impregnam-se das experiências calcadas nas relações de classe e por aí se definem.

Decerto mais uma vez se perguntaria se estamos depositando um excesso de confiança no papel da escola. Antes assim, penso eu. Mas a educação, e não menos a dos professores, é um bem que, em sua aquisição, transforma-se em poder, ou não é nada. Uma cultura da atenção incluiria o favorecimento a essas formas de se reconhecer e de reconhecer ao outro. E ainda seria preciso pensar essa cultura da atenção como geradora de atitudes mediante as quais se ausculta a realidade, se olha para ver o outro, observa a si próprio como sujeito/ objeto de conhecimento.

Assim, tal como me parece, entre as crenças não destruídas acerca das possibilidades da educação, a hipótese de uma cultura da atenção permitiria explorar a percepção de si e do outro no mundo social buscando fornecer-lhe a mais ampla compreensão possível da própria vida da cultura e da sociedade, permitiria ainda apreender que essa mesma "[...] vida de uma cultura e de uma sociedade é feita de um incessante vai e vem entre as realidades, representações e sua memorização: o futuro e o presente dependem de uma arqueologia de gestos, objetos, palavras, imagens, formas e símbolos, repertórios de múltiplas entradas a partir do qual se compõe uma paisagem de comunicação e se inventam as proposições da inovação".

É ainda pelas mãos do Michel de Certeau que podemos encontrar, na sequência, outras aberturas para instalar as possibilidades educativas:

Cultura e comunicação alimentam-se de relatos, não só para conservar piedosamente os grandes momentos do passado, nem com a vã esperança de armar o catalogo completo de um patrimônio, mas sim para engendrar o futuro a partir do presente ao reinscrever vale a marca do passado (1994, p. 211). 
Pois bem, quais são os relatos que estamos favorecendo com nossa educação para os professores? Onde a nossa atenção para com os relatos de si? Servem os relatos da sociologia, da psicologia ou da história que ensinamos aos desígnios de cultivar a atenção? Que atenção é possível a partir dessa educação feita para professores, hoje, para que todas as pessoas possam dar-se conta de que "os gestos, objetos, palavras, imagens, formas e símbolos", "os repertórios de múltiplas entradas", devem dispor-se para todos que têm direito de com eles, ou a partir deles, reinventar sua própria história.

\section{Reflexões finais: o que tem sido sonegado nos processos formativos educacionais de professores da universidade?}

As possibilidades de uma educação fecunda partilháveis eram consideradas por Bourdieu, que parecia disposto a considerá-la como dispositivo de luta, para o qual se deverá ensinar como se fabrica, com que materiais, quem vai manejá-los melhor e como superar as próprias desvantagens sociais. Se a educação de professores não for assim, como esperar que a educação de todos seja uma hipótese de invenção de si? Como esperar que todos possam construir seus relatos e nomear sua própria história? Que possam situar-se em temporalidades promissoras que se configuram como confluências do passado-presente e futuro e não apenas como um presente eterno e fugidamente tensionado.

Decerto, embora não seja o caso de estender-se sobre este ponto, uma cultura da atenção incluiria movimentos de produção e de acolhida de uma nova história da educação, dos professores, dos alunos, mais disposta a perceber sob o que Certeau chama de "nuvens de histórias" as das relações dos sujeitos com suas realidades, suas culturas, seu trabalho ou seus ofícios. Pois bem, nas práticas de formação uma das vias não deveria justamente favorecer a tematização dessas relações? Perigosa sugestão essa de que a educação faça do melhor modo possível o que sempre deveria ter feito: permitir um percurso que só tem sentido se, ao ampliar e problematizar as relações com a realidade, permita a atenção simultânea ao individual e singular tanto quanto ao universal e permita um trânsito constante entre esses reconhecimentos.

É o caso de se temer, hoje, que nossos bem intencionados investimentos pelas reformas curriculares criem apenas projetos perfeitos de distribuição equitativa de informações e disciplinas e que não comecemos jamais a indagar em quais relações apostamos como fundadoras ou como passíveis de servir de sustentáculo de uma cultura de atenção. Enquanto uma hipótese de educação 
essa deveria nos levar ao confronto com questões como as seguintes: sabemos como favorecer na formação de professores a compreensão e a análise dos seus próprios modos de estar atentos a si e aos outros? Sabemos como educá-los para que possam explicitar para si até as últimas consequências os processos de construção das relações com o conhecimento, os valores, as formas de estar na realidade?

Por fim, uma cultura de atenção encontra nesse momento terreno fértil para que tentemos transformar a educação de professores a partir de uma transformação de relações, consigo, com o outro e com o mundo. Tais são as dimensões vitais que temos sonegado em nossos processos educacionais. Seria talvez necessário que os aprendizados para a docência fossem parte de um projeto de formação humanística mais enérgico quanto aos seus elos com as racionalidades cognitiva, ética e estética e menos ambicioso quanto aos seus anseios estritamente didático-pedagógicos.

\section{REFERÊNCIAS}

BOURDIEU, P. A Economia das Trocas Simbólicas (Org. Sérgio Miceli) 6. ed. São Paulo, Perspectiva, 2005.

BOURDIEU, P. CHAMBOREDON, J. C.; PASSERON, J. C. A profissão de Sociólogo - Preliminares epistemológicas. Petrópolis, Rio de Janeiro: Vozes, 1999.

BOURDIEU, P. Esquisse d'une theorie de la pratiqu. Genève: Ed. Droz, 1972.

BOURDIEU, P.; WACQUANT, LoÏc, J. D. Réponses - pour une anthropologie réflexive. Paris: Ed. du Seuil, 1992.

CATANI, D. B. A autobiografia como saber e a educação como invenção de si. In: SOUZA, Elizeu Clementino de; ABRAHÃO, Maria Helena Menna Barreto. (Org.). Tempos, narrativas e ficções: a invenção de si. Porto Alegre: EDIPUCRS, 2006. p. 77-87.

CATANI, D. B. A didática como iniciação: uma alternativa no processo de formação de professores. In: CASTRO, A. D.; Ana Maria Pessoa CARVALHO. (Org.). Ensinar a ensinar: didática para a escola fundamental e média. São Paulo: Pioneira, 2001. p. 53-72. 
CATANI, D. B. Práticas de Formação e o Ofício Docente. In: BUENO, B. O.; SOUSA, C. P.; CATANI, D. (Org.). A vida e o ofício dos professores. 1. ed. São Paulo: Escrituras Editora, 1998. p. 23-30.

CATANI, D. B. A Formação de Professores e o Desempenho Pedagógico. In: FISCHMAN, Roseli. (Org.). A Escola Brasileira: temas e estudos. São Paulo: Atlas, 1987. p. 161-169.

CATANI, D. B.; GALlEGO, R. C. Avaliação. São Paulo: Ed. UNESP, 2009.

CERTEAU, M. de. La prise de parole et autres écrits politiques, Paris: Ed. du Seuil, 1994.

LUGLI, R. S. G. A constituição social do indivíduo. In: LUGLI, R. S. G. Educação Biblioteca do Professor, Bourdieu Pensa a Educação, n. 5, p. 26/35, 2006.

LUGLI, R. S.G. O trabalho docente no Brasil: o discurso dos Centros Regionais de Pesquisa Educacional e das entidades representativas do magistério (1950-1971). Tese (Doutorado) - FEUSP, São Paulo, 2002.

PERRENOUD, P. Práticas Pedagógicas, Profissão Docente e Formação - Perspectivas Sociológicas. Lisboa: Publicações Dom Quixote, 1993.

PETERS, R. S. Educação como iniciação. In: ARCHAMBAULT, R. D. (Org.). Educação e Análise Filosófica. São Paulo: Saraiva, 1979. p. 101-130.

Texto recebido em 19 de fevereiro de 2010.

Texto aprovado em 23 de fevereiro de 2010. 